Preference is given to letters commenting on contributions published recently in the JRSM. They should not exceed 300 words and should be typed double spaced

\section{The surgeon's job}

Professor Rowley (August $2004 J R S M^{1}$ ) correctly identifies Skills for the New Millennium: Report of the Societal Needs Working Group CanMEDS 2000 as an influential document identifying necessary elements in the area of professionalism. However, he errs in indicating it was a product of the Canadian Medical Association. It was authored by a working group of the Royal College of Physicians and Surgeons of Canada (RCPSC). The CanMEDS framework was developed and validated from 1993 to 1996. It was incorporated into Canadian specialty postgraduate education during the next six years along with enhanced material for faculty development. The CanMEDS framework of competencies that began as an initiative of forward-thinking Fellows of the RCPSC has become a popular standard for medical education around the world, including Australia, the Netherlands, Denmark and the UK.

\section{Henry Dinsdale}

95 Hill Street, Kingston ON, Canada K7L 2M8

\section{REFERENCE}

1 Rowley DI. The surgeon's job: how should we assess trainees? J R Soc Med 2004;97:363-5

\section{Achilles tendinopathy}

The juxtaposition of articles on statins and Achilles tendinopathy in the October 2004 JRSM reminded me of a case relevant to the article by Maffulli and colleagues. ${ }^{1} \mathrm{~A}$ young man was referred to me with a raised cholesterol (LDL approximately $7 \mathrm{mmol} / \mathrm{L}$ ) and a family history of premature coronary heart disease. On history-taking it emerged that the patient had recently developed unilateral tendinitis, for which he had received peritendinous injections of corticosteroids. On examination he had bilateral corneal arcus and Achilles tendon xanthomata. Heterozygous familial hypercholesterolaemia was diagnosed and he was started on a statin.

The association between familial hypercholesterolaemia and Achilles tendinitis is well known. ${ }^{2,3}$ Treatment of the hypercholesterolaemia will probably lead to resolution of the tendinitis ${ }^{4}$ but, more importantly, it may prevent a premature death. I advise looking at the eyes as well as the legs.

\section{Gordon Ferns}

Clinical Laboratories, Royal Surrey County Hospital, Guildford GU2 7XX, UK E-mail: G.ferns@surrey.ac.uk

\section{REFERENCES}

1 Maffulli N, Sharma P, Luscombe KL. Achilles tendinopathy: aetiology and management. J R Soc Med 2004;97:472-6

2 Mathon G, Gagne C, Brun D, Lupien PJ, Moorjani S. Articular manifestations of familial hypercholesterolaemia. Ann Rheum Dis 1985;44:599-602

3 Handel ML, Simons L. Rheumatic manifestations of hyperlipidaemia. Baillière's Best Pract Res Clin Rheumatol 2000;14:595-8

4 Klemp P, Halland AM, Majoos FL, Steyn K. Musculoskeletal manifestations in hyperlipidaemia: a controlled study. Ann Rheum Dis 1993;52:44-8

\section{Textbook of Tropical Surgery}

Imre Loefler (September $2004 J^{2} S M^{1}$ ) compares the new Textbook of Tropical Surgery unfavourably with Principles of Medicine in Africa. However, the latter is in its third edition whereas, as he acknowledged, the editors of the surgical textbook had 'embarked on a task never undertaken before'. I write as one of the 265 contributors from thirtynine countries. Some of $\mathrm{Mr}$ Loefler's points require attention and we are grateful for the critique; others stem from the editors' aim to bridge the gap between developed and developing countries. This mammoth surgical work has no rivals, and doubtless when the time comes for second and third editions it will withstand better comparison with the medical book.

\section{Ahmes L Pahor}

34, Ingham Way, Harborne, Birmingham B17 8SN, UK

\section{REFERENCE}

1 Loefler I. Principles of Medicine in Africa and Textbook of Tropical Surgery [Book Review]. J R Soc Med 2004;97:451-2

\section{The sickly Stuarts}

Neither in Milo Keynes' review of Professor Holmes' book The Sickly Stuarts - the Medical Downfall of a Dynasty (June $2004 J R S M^{1}$ ) nor in Graham Brack's comments on the review (August $2004 \mathrm{JRSM}^{2}$ ) is mention made of Holmes' view of the hypothesis that James VI/I suffered from familial porphyria. Having described the renal findings at the necropsy of James VI/I, Holmes writes 'this finding negates and lays to rest the presumption of $\mathrm{Dr} I d a$ Macalpine and her colleagues that James and his mother had acute intermittent porphyria ... unfortunately this idea has had a life of its own....' Having cited publications opposing the porphyria hypothesis, Holmes concludes 'James did not have porphyria. Nor, for that matter, did any of the Stuarts or Hanoverians'. In the subsequent paragraph, he states 'The clinical description of de Mayerne and the autopsy report of Walton provide a clear description of chronic kidney stone disease'. ${ }^{3}$ 
Although Macalpine and Hunter ${ }^{4}$ are supported by Rohl, Warren and Hunt, ${ }^{5}$ Holmes' contrary view needs to be made known to a wider readership than those who have read his book.

\section{E D Myers}

St David's, 96 Lancaster Road, Newcastle, Staffordshire ST5 1DS, UK

E-mail: tedsyb@ntlworld.com

\section{REFERENCES}

1 Keynes M. The Sickly Stuarts - the Medical Downfall of a Dynasty [Book Review]. J R Soc Med 2004;97:306-7

2 Brack G. The Sickly Stuarts [Letter]. J R Soc Med 2004;97:412

3 Holmes F. The Sickly Stuarts - the Medical Downfall of a Dynasty. Gloucestershire: Sutton Publishing, 2003;51-2

4 Macalpine J, Hunter, R. George III and the Mad-Business. London: Pimlico, 1991:201-9

5 Rohl J, Warren M, Hunt D. Purple Secret: 'Madness' and the Royal Houses of Europe. London: Bantam, 1998

\section{Coxibs and serious adverse cardiovascular events: a class-effect?}

Selective cyclo-oxygenase-2 (COX-2) inhibitors, sometimes referred to as 'coxibs', are widely prescribed by hospital doctors and general practitioners for arthritic pain. Their gastrointestinal tolerability is believed to be superior to that of 'non-selective' non-steroidal anti-inflammatory drugs (NSAIDs) such as naproxen and diclofenac. Since the US Food and Drug Administration (FDA) approved the use of rofecoxib (Vioxx) in May 1999, 83 million prescriptions have been issued worldwide. However, on 30 September 2004, rofecoxib was voluntarily withdrawn by Merck Sharp \& Dohme because of an increased relative risk of serious cardiovascular events seen after 18 months' use in the APPROVe (Adenomatous Polyp Prevention On Vioxx) trial. The APPROVe trial was initiated because of two previous studies 1,2 indicating that daily aspirin had protective effects against colorectal adenomas.

The finding of increased risk of cardiovascular events in relation to rofecoxib did not come as a complete surprise. Such an effect was evident in the Vioxx Gastrointestinal Outcomes Research (VIGOR) ${ }^{3}$ study, the results of which were reported almost 4 years ago. Results for the first 6 months from a similarly large trial of another selective COX-2 inhibitor, the Celecoxib Long-term Arthritis Safety Study (CLASS), ${ }^{4}$ suggested that celecoxib had a better gastrointestinal toxicity profile than diclofenac or ibuprofen but results for the 12 month period, made available on the FDA website, ${ }^{5}$ do not entirely support this conclusion. The discrepancy generated criticism of the way the CLASS data were initially reported. ${ }^{6}$ Moreover, although celecoxib was not associated with a higher risk of serious cardiac sequelae than diclofenac or ibuprofen over the whole duration of the trial, the data do not exclude the possibility of lesser effects related to cardiac ischaemia.

When an unexpected drug effect is observed, whether adverse or beneficial, the possibility of a 'class-effect' has to be considered. So, might adverse cardiovascular effects be expected with COX-2 agents other than rofecoxib? This question will need to be addressed with complete transparency in future studies of COX-2 inhibitorsespecially with the advent of agents such as valdecoxib (Bextra), the successor drug of celecoxib, and etoricoxib (Arcoxia), planned successor of the withdrawn rofecoxib. Meanwhile, for the purposes of alleviating arthritic pain at least, COX-2 inhibitors have lost some of their attraction compared with the older NSAIDs such as diclofenac in combination with a proton pump inhibitor (omepraxole). ${ }^{7}$

\section{Jon K C Yoong}

Department of Rheumatology \& Immunology,

Singapore General Hospital, Singapore 169608

E-mail: jonyoong@yahoo.com

\section{REFERENCES}

1 Sandler RS, Halabi S, Baron JA, et al. A randomized trial of aspirin to prevent colorectal adenomas in patients with previous colorectal cancer. N Engl J Med 2003;348:883-90

2 Baron JA, Cole BF, Sandler RS, et al. A randomized trial of aspirin to prevent colorectal adenomas. N Engl J Med 2003;348:891-9

3 Bombardier C, Laine L, Reicin A, et al. Comparison of upper gastrointestinal toxicity of rofecoxib and naproxen in patients with rheumatoid arthritis. N Engl J Med 2000;343:1520-8

4 Silverstein FE, Faich G, Goldstein JL, et al. Gastrointestinal toxicity with celecoxib vs nonsteroidal anti-inflammatory drugs for osteoarthritis: the CLASS study: a randomized controlled trial. Celecoxib Long-term Arthritis Safety Study. JAMA 2000;284:1247-55

5 Witter J. Medical Officer review [www.fda.gov/ohrms/dockets/ac/ 01/briefing/3677b103med.pdf]

6 Hrachovec JB, Mora M. Reporting of 6-month vs 12-month data in a clinical trial of celecoxib. JAMA 2001;286:2398-400

7 Chan FK, Hung LC, Suen BY, et al. Celecoxib versus diclofenac and omeprazole in reducing the risk of recurrent ulcer bleeding in patients with arthritis. N Engl J Med 2002;347:2104-10

\section{Adult bone-marrow stem cells}

In their paper about the therapeutic potential of adult bonemarrow stem cells (October $2004 J_{R S M^{1}}$ ) Professor Hassan and Dr El-Sheemy refer to ethical controversies over use of embryonic stem cells. Apart from the ethical objections, cell replacement therapy from embryos and fetal tissue is complicated by difficulties with standardizing the procedure, ensuring viability of tissue and obtaining tissue at optimal time points. By induction of fate-specific cells from an in-vitro-expanded population of isolated progenitor/stem cells, bone marrow stem cells may be more readily exploited. Differentiation of expanded cells can be induced 
by mitogen withdrawal or by exposure to cytokines, hormones or vitamins that cause lineage restriction.

Cytokines involved in the clonal expansion and lineage restriction of stem/progenitor cells in the haematopoietic system may play an important analogous role in the developing nervous system. For example, interleukin-1 can induce expression of the dopaminergic marker tyrosine hydroxylase. Furthermore, in a study by Carpenter et al. ${ }^{2}$ leukaemia inhibitory factor, a member of the interleukin-6 cytokine family, when combined with other mitogens was shown to enhance proliferation of human forebrain neural stem cells. Importantly, we need to consider the possibility that bone marrow stem cells are able to redifferentiate. Already there is evidence that neural stem cells can become bone-marrow-like: they were shown capable of reconstituting the haematopoietic systems of mice that had undergone marrow ablation. ${ }^{3}$ These studies suggest that the lineage path taken by multipotent cells is influenced by the environments to which they are exposed.

\section{Suneeta Kochhar}

St Thomas' Hospital, London SE1 7EH, UK

E-mail: suneetakochhar@doctors.org.uk

\section{REFERENCES}

1 Hassan HT, El-Sheemy M. Adult bone-marrow stem cells and their potential in medicine. J R Soc Med 2004;97:465-71

2 Brazelton TR, Rossi FM, Keshet GI, Blau HM. From marrow to brain: expression of neuronal phenotypes in adult mice. Science 2000;290:1775-9

3 Carpenter MK, Cui X, Hu ZY, et al. In vitro expansion of a multipotent population of human neural progenitor cells. Exp Neurol 1999;158:26578

\section{Diathermy and tonsillectomy: criticism of NICE}

Earlier this year the National Institute for Clinical Excellence (NICE) issued guidelines for use of diathermy in tonsillectomy, based on a nationwide audit that is still continuing. A letter issued by $\mathrm{Mr}$ Andrew Dillon, Chief Executive, and Professor Bruce Campbell, C Chair of the Interventional Procedures Committee, advised that 'all surgeons should consider how best to minimize their use of diathermy during the tonsillectomy' [www.nice.org.uk/ page.aspx?o=203699]. As the surgeon who does most of the adult tonsillectomies in my hospital, I have found this advice both puzzling and disruptive. An immediate consequence was that the 'risk management' section of our trust expressed grave concern that diathermy (bipolar in our case) was being used in our department. Within a fortnight a departmental policy was created stating that diathermy may be made available only if all attempts at controlling bleeding with ligatures have failed. When does ligating every red object in the tonsillar bed, all bleeds eventually stop. The surgeon now feels guilty even about mentioning diathermy.

Having looked at the 'evidence', I wonder why NICE was in such a hurry to release this interim guideline before reaching definitive conclusions. Take the chart providing figures for 'cold steel dissection with diathermy haemostasis' (the method I use). No distinction is made between monopolar and bipolar types even though the audit form differentiates between the two. We are told that patients operated in this way are $0.7 \%$ more likely to return to theatre with postoperative bleeding than those in whom ligatures only are used. Since the document later states that the monopolar type is twice as harmful as the bipolar type, we might reasonably assume that in patients receiving bipolar diathermy for haemostasis the excess risk of returning to theatre will be even less than $0.7 \%$. Should we really change our practice on the basis of this very small difference and lose the advantages that bipolar haemostasis has to offer — notably, a much quicker operation and less preoperative blood loss (both matters on which the 'interim guidance' is silent)? The practical advantages of bipolar dissection have been well discussed by Silveira et al. ${ }^{1}$ In presenting its haemorrhage figures, NICE states that patients operated upon by trainees are roughly twice as likely to bleed as those operated on by non-training grades and consultants. Unfortunately, this difference is not allowed for in discussion of individual methods. If, for example, cold steel tonsillectomy with ligature haemostasis is done mainly by experienced surgeons while the younger generation favour diathermy, that might explain the apparent advantages of the former. Many aspects of the interim guidance are in conflict with recent studies. Both Belloso et $a .^{2}$ and Timms ${ }^{3}$ have reported lower rates of postoperative bleeding with coblation than with cold-steel dissection and bipolar haemostasis. Moreover, in a review of the published work, Leinbach et al. ${ }^{4}$ showed no significant difference in postoperative bleeding between monopolar dissection and cold steel dissection.

By presenting its confusing interim guidance NICE breached a basic principle of audit that changes are effected only after the data collection phase of the audit is over; otherwise the final assessment is falsified. For example, whereas before the guidelines nearly all the tonsillectomies at our hospital involved diathermy, the procedure is now almost extinct - yet the data collection phase is yet not over. As it happens, the number of post-tonsillectomy bleeds has slightly increased, though (as with some of the differences in the NICE document) this may be due to chance.

\section{Aamir Shahzad}

E-mail: mera_nam@yahoo.co.uk 


\section{REFERENCES}

1 Silveira H, Soares JS, Lima HA; Tonsillectomy: cold dissection versus bipolar electrodissection. Int J Paediatr Otorhinolaryngol 2003;67:345-51

2 Belloso A, Chidambaram A, Morar P, Timms MS; Coablation tonsillectomy versus dissection tonsillectomy: postoperative hemorrhage. Laryngoscope 2003;113:2010-13

3 Timms M. Coblation tonsillectomy: a personal view. ENT News 2004; No. 13:40-1

4 Leinbach RF, Markwell SJ, Colliver JA, Lin SY. Hot versus cold tonsillectomy: a systemic review of the literature. Otol Head Neck Surg 2003;129:360-4

\section{Reply from NICE}

The interim guidance [www.nice.org.uk/interimtonsillectomy guidance] was issued in response to a request from the Chief Medical Officers of England, Scotland and Northern Ireland to review urgently the use of diathermy tonsillectomy, and followed an interim analysis of the results of the National Prospective Tonsillectomy Audit which was carried out in England and Wales. The results ${ }^{1}$ suggested that there was a higher risk of secondary haemorrhage requiring readmission to hospital and return to theatre after tonsillectomy using diathermy techniques or coblation compared with techniques which use no diathermy either for dissection or haemostasis.

This advice was issued in conjunction with an accompanying letter from Professor Richard Ramsden, Chairman of the Audit Steering Group, in which he summarized the results [www.nice.org.uk/pdf/ diathermytonsillectomyletterrichardramsden.pdf]. The interim guidance advised that all surgeons should consider how best to minimize their use of diathermy during tonsillectomy, particularly when diathermy is being used for both dissection and haemostasis. It highlighted that the risk may be particularly high for monopolar diathermy and surgeons should consider discontinuing this method. The risk may also be higher with currently available disposable diathermy equipment for tonsillectomy and again surgeons should consider discontinuing use of such equipment. In addition the Institute advised that the National Prospective Tonsillectomy Audit should continue and that all patients having tonsillectomy should be included.

In advising the Institute on this matter, the Interventional Procedures Advisory Committee were aware of the methodological challenges of assessing interim data, some of which have been raised by Mr Shahzad. The Institute will issue full guidance when a systematic review of the literature together with a more detailed analysis of the audit data is available.

In view of the concerns raised by the British Association of Otorhinolaryngologists, Head and Neck Surgeons' audit we consider that the Institute has taken a measured and appropriate approach to ensuring patient safety.

\section{Bruce Campbell ${ }^{1}$ Peter Littlejohns ${ }^{2}$}

${ }^{1}$ Chairman, Interventional Procedures Advisory Committee and

${ }^{2}$ Clinical Director, National Institute for Clinical Excellence, MidCity Place,

71 High Holborn, London WC1V 6NA, UK

\section{REFERENCE}

1 National Prospective Tonsillectomy Audit. Tonsillectomy technique as a risk factor for postoperative haemorrhage. Lancet 2004;364:697-702

\section{Referral criteria in early rheumatoid arthritis}

Dr Suresh (September $2004 J R S M^{1}$ ) highlights the importance of early referral in a patient with suspected rheumatoid arthritis or RA-like polyarthritis. As he indicates, the diagnosis is a clinical one and absence of rheumatoid factor (RF) is not informative. Unfortunately, there is reason to think some general practitioners delay referral when the serology is negative. Sinclair and Hull, ${ }^{2}$ looked at the reasons general practitioners request $\mathrm{RF}$ assays and the effect of the result on their subsequent action. The requests were generally backed by appropriate clinical signs of RA; however, $32 \%$ of responders believed that a negative RF excluded RA, even in a patient who fulfilled the American Rheumatism Association ${ }^{4}$ classification criteria. Referrals were made to a consultant rheumatologist in 52\% of patients with a positive RF, but $66 \%$ of patients with a negative RF would not be referred. In only $1.2-2.5 \%$ of instances were patients referred for specialist review on clinical grounds alone. Seronegative RA should account for about $25 \%$ of total cases. With $60 \%$ of cases seronegative at presentation, ${ }^{5}$ the above data suggest that a sizeable number of RA patients are being missed. Should RF be removed from the decision-making process? If general practitioners relied wholly on clinical criteria and the RF test was restricted to rheumatologists only, we could expect a large increase in consultant referrals.

\section{Vicki Quincey \\ R Hull}

D Sinclair

Department of Rheumatology, Queen Alexandra Hospital,

Portsmouth PO6 3LY, UK

E-mail: vaquincey@hotmail.com

\section{REFERENCES}

1 Suresh E. Diagnosis of early rheumatoid arthritis: what the nonspecialist needs to know. J R Soc Med 2004;97:421-6

2 Scott DL. Prognostic factors in early rheumatoid arthritis. Rheumatology 2000;39(suppl 1):24-9

3 Sinclair D, Hull RG. Why do general practitioners request rheumatoid factor? A study of symptoms, requesting patterns and patient outcome. Ann Clin Biochem 2003;40:131-7

4 Arnett FC, Edworth SM, Bloch DA, et al. The American Rheumatism Association 1987 revised criteria for the classification of rheumatoid arthritis. Arthritis Rheum 1988;31:315-24

5 Emery P. The Dunlop-Dottridge Lecture: prognosis in inflammatory arthritis: the value of HLA genotyping and the oncological analogy. $J$ Rheumatol 1997;24:1436-42 


\section{Compulsory helmets for cyclists}

Professor Sheikh and colleagues (June $2004 J R S M^{1}$ ) favoured legislation that would compel cyclists to wear helmets. They conceded that the ethical argument was somewhat stronger for children than for adults. Subsequent correspondents questioned the evidence on helmet efficacy and argued that legislation would have negative effects by discouraging the healthful activity of bicycling. When analysing the cost-benefit ratio of legislation we should factor in the full effects which flow from traumatic brain injury, not only to the patient but also to the patient's family and carers. ${ }^{2,3}$ These involve many levels ranging from the formally quantifiable health costs, through changes in quality and quantity of life, to the less measurable personal, family and social losses. Wearing seat belts in motor vehicles now seems common sense and has reduced the neurological burden imposed by accidents. Wearing helmets by all cyclists should also seem common sense. Combined with public health campaigns on the long-term benefits of exercise, any potential negative impact of mandatory helmet-wearing should disappear. We have already accepted the impositions on our freedom of movement (e.g. airports and elsewhere) brought about by the global terrorist threat. In many countries the risk of traumatic brain injury following a cycle accident may be much greater than a terrorist threat.

\section{Simon Gandevia}

Prince of Wales Medical Research Institute, University of New South Wales, Sydney NSW 2031, Australia

\section{REFERENCES}

1 Sheikh A, Cook A, Ashcroft R. Making cycle helmets compulsory: ethical arguments for legislation. J R Soc Med 2004;97:262-5

2 Hendrie D, Legge M, Rosman D, Kirov C. An economic evaluation of the mandatory helmet legislation. University of Western Australia Public Health Department. [www.officeofroadsafety.wa.gov.au/Facts/ papers/bicycle_helmet_legislation.html]

3 Kneafsey R, Gawthorpe D. Head injury: long-term consequences for patients and families and implications for nurses. J Clin Nurs 2004;13:601-8 